\title{
Combined APT, TEM and SAXS Characterisation of Nanometre-Scale Precipitates in Titanium Alloys
}

\author{
FF Dear ${ }^{*}$, P Kontis ${ }^{2}$, B Gault ${ }^{1,2}$, J Ilavsky $^{3}$, H Gardner $^{4}$, PAJ Bagot ${ }^{4}$, MP Moody ${ }^{4}$, D Rugg and D Dye $^{1}$ \\ 1. Department of Materials, Imperial College London, London, UK. \\ 2. Max-Planck-Institut für Eisenforschung, Düsseldorf, Germany. \\ 3. X-ray Science Division, Argonne National Laboratory, Argonne, USA. \\ 4. Department of Materials, Oxford University, Oxford, UK. \\ 5. Rolls-Royce plc, Derby, UK. \\ * Corresponding author: ffd15@ic.ac.uk
}

Advances in aero engine technology require constant innovation in development and in-service management of key engineering materials. Improvements to alloy performance and component management relating to fatigue cracking depend on mechanistic understanding of damage accumulation processes at the atomic scale, such as the influence of alloying elements on slip behaviour in $\alpha+\beta$ titanium alloys. Many of these materials contain sufficient aluminium for thermomechanical processing to induce nanometre-scale precipitation of the crystallographically ordered $\alpha_{2}\left(\mathrm{Ti}_{3} \mathrm{Al}\right)$ phase. This phase impedes dislocation motion, causing intragranular slip heterogeneity that leads to high micromechanical stresses and ultimately increases the propensity for fatigue crack initiation [1].

Previous studies have indicated an influence of tertiary solutes on $\alpha_{2}$ formation and structure. Interstitial oxygen is known to encourage phase separation [2], while the presence of beta-stabilisers such as $\mathrm{V}$ and Mo has been linked to modification of the precipitate dispersion [3]. A model alloy series designed to isolate the influences of $\mathrm{O}, \mathrm{V}$ and $\mathrm{Mo}$ in alpha $\mathrm{Ti}-7 \mathrm{Al}$ (wt.\%) has been subjected to an isothermal ageing study to generate precipitate dispersions as a function of time and composition. Initial characterisation with selected area diffraction and dark field imaging in conventional TEM revealed differences in the number density and size evolution of precipitates, Figure 1. Quantification of dispersion statistics (number density, volume fraction and size distribution) and phase compositions is unfeasible with TEM or STEM techniques, due to the fine length scales involved and the low concentrations of the tertiary solutes of interest.

Atom probe tomography has been used to characterise the spatial distribution of key solutes after precipitate formation, with particular interest in the phase segregation of interstitial oxygen, Figure 2. Voltage mode measurements were conducted using a Cameca LEAP 5000XS. Specimens were prepared using conventional FIB lift-out techniques [4], on grains of $\{2 \overline{11} 0\}$ orientation in order to repeatably capture the precipitate crystallography. Across all alloys studied in this work, oxygen was found to segregate to the $\alpha$ matrix phase, despite encouraging the formation of $\alpha_{2}$ precipitates. This indicates an indirect effect of increased oxygen content on $\alpha_{2}$ formation [5], and a possible link to vacancy concentration is being investigated. Vanadium was found to partition out of the precipitate phase, while molybdenum showed no conclusive segregation to either phase.

Small angle X-ray scattering experiments were performed on the USAXS beamline at the Advanced Photon Source, Argonne National Laboratory, USA. These data provide quantification of the increase in nucleation density upon increasing oxygen content, observed in TEM both in the Ti-Al binary alloy and 
in ternary Ti-Al-V and Ti-Al-Mo alloys. A subtle influence of vanadium on precipitate size distribution and volume fraction was observed, while molybdenum significantly retards the kinetics of the phase separation process. The size and atomic number similarity of titanium and vanadium likely explains the minimal impact of vanadium on this phase transformation. Slowing of phase transformation kinetics by molybdenum in titanium alloys is a known and expected behaviour of this solute [6].

Through the combination of TEM, SAXS and APT, quantification of precipitate dispersion features and solute distribution has been achieved, offering meaningful insight into this industrially important process. The precipitation behaviour of $\alpha_{2}$ in Ti-Al-X alloys was observed to be sensitive to changes in oxygen content, considerably slowed by the presence of molybdenum, and only minimally responsive to the presence of vanadium [7].

\section{References:}

[1] MC Brandes, MJ Mills and JC Williams, Metall. Mater. Trans. A 41(13) (2010), p. 3463.

[2] DJ Truax and CJ McMahon, Mater. Sci. Eng., 13(2) (1974), p. 125.

[3] A Radecka et al., Acta Mater. 112 (2016), p. 141.

[4] K Thompson et al., Ultramicroscopy 107(2-3) (2007), p. 131.

[5] PAJ. Bagot et al., Scripta Mater. 148 (2018), p. 24.

[6] SL Semiatin, JC Soper and IM Sukonnik, Acta Mater. 44(5) (1996), p. 1979.

[7] The authors acknowledge funding from EPSRC grant number EP/L015277/1 and Rolls-Royce plc.

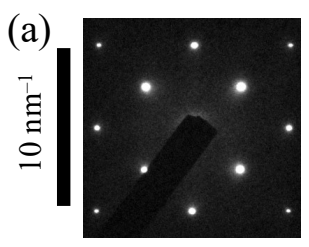

0 hours

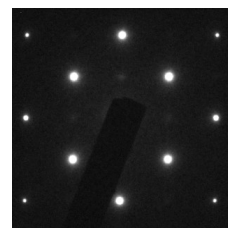

2 hours

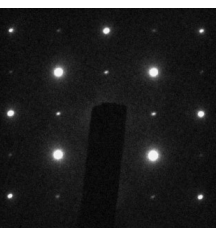

240 hours

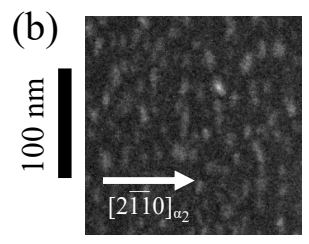

Ti-7Al

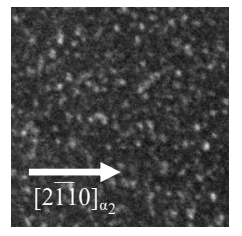

Ti-7Al-0.25O

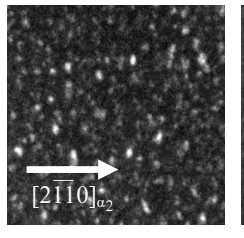

Ti-7Al-1.1V

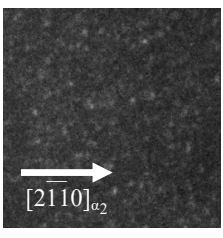

Ti-7Al-0.9Mo

Figure 1. Selected area diffraction patterns, $\mathrm{B}=[01 \overline{1} 1]$, for Ti-7Al (wt.\%) after isothermal ageing at $550{ }^{\circ} \mathrm{C}$ for 0,2 and 240 hours (a) show superlattice reflections indicating growth of $\alpha_{2}$ precipitates. After 240 hours, dark field TEM images (b) $\left(\mathrm{B}=[01 \overline{1} 1], \mathrm{g}=[2 \overline{11} 0]_{\alpha_{2}}\right)$ show the modifications to number density, size and morphology caused by tertiary solutes in $\mathrm{O}, \mathrm{V}$ and Mo-containing alloy variants.

(a)

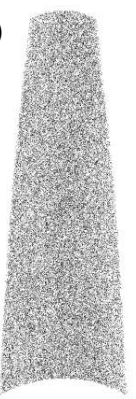

$\mathrm{Ti}$

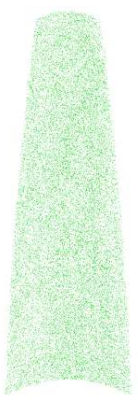

$\mathrm{TiO}$

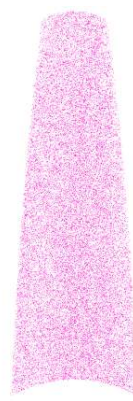

$\mathrm{V}$

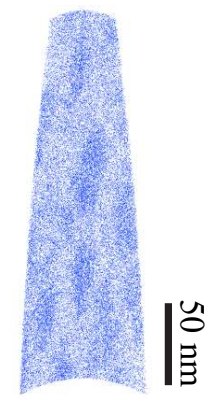

$\mathrm{Al}$ (b)

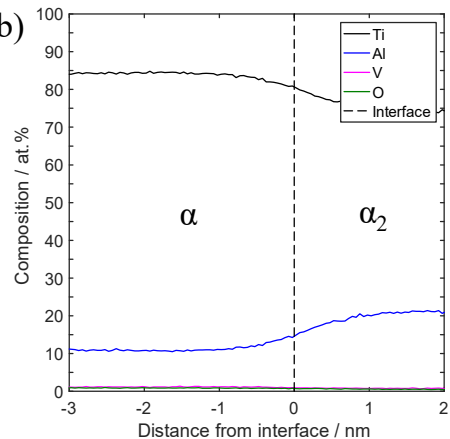

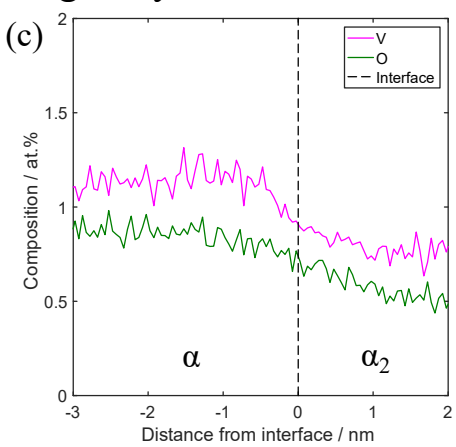

Figure 2. Atom probe tomography characterisation of $\alpha_{2}$ precipitates has allowed exploration of the phase segregation of additional solutes such as $\mathrm{O}, \mathrm{V}$ and Mo. In this sample, a Ti-7Al-1.1V-0.25O (wt.\%) alloy has been aged for 1175 hours to grow Al-rich $\alpha_{2}$ precipitates (a), for which proximity histograms (b) show segregation of $\mathrm{V}$ and $\mathrm{O}$ to the matrix $\alpha$ phase rather than precipitates. 